\title{
Experimental and Numerical Failure Analysis of Adhesive Joint of Glass Fiber Reinforced Polymer Composite
}

\author{
László Takács ${ }^{1,2}$, Ferenc Szabó ${ }^{1 *}$ \\ 1 Department of Polymer Engineering, Faculty of Mechanical Engineering, Budapest University of Technology and Economics, \\ H-1111 Budapest, Múegyetem rkp. 3., Hungary \\ 2 eCon Engineering Kft., H-1116 Budapest, Kondorosi str. 3., Hungary \\ *Corresponding author, e-mail: szabof@pt.bme.hu
}

Received: 13 October 2019, Accepted: 03 December 2019, Published online: 17 December 2019

\begin{abstract}
The adhesive joint is the most widely used joining technique of thermoset composite structures. Analysis of the failure of adhesive joints of composite structures has a high importance due to its significance in industrial applications such as automobile or autobus bodies. In this paper we performed experimental and numerical analysis of a glass fiber reinforced, vinyl-ester matrix composite bonded with a methacrylate adhesive. The critical energy release rate in normal loading direction obtained from standard double cantilever beam test is used as input data in finite element simulations, in which the failure process is modeled by using cohesive zone material. Results of interface elements with exponential and standard contact elements with bilinear cohesive behavior are compared. The use of interface elements is numerically robust, convergence is reached faster, but identical mesh between the parts is needed. It can be a good alternative when simulating sub-models. When using standard contact elements, the robustness needs contact stabilization, however this method does not need identical mesh and it also allows the use of shell elements, therefore it can be used on a full-structure scale with high efficiency.
\end{abstract}

Keywords

composite, adhesive joint, FEM, cohesive zone

\section{Introduction}

Polymer composite structures play an increasing role in the automobile industry due to their excellent stiffness and strength to weight ratio. One of the key elements to fulfill the emission norms and reduce fuel consumption is weight reduction. The most widespread method of joining thermoset composites is the adhesive joint [1]. Extensive studies have been conducted on understanding the failure of adhesive joints by both experimental and calculation methods.

The basic experiments are the standard double-cantilever beam test (DCB) and the end-notched flexure test (ENF) to measure fracture toughness of mode I and mode II loadings. Oshima et al. [2] introduced a new method to evaluate DCB specimens with wedge loading. Arrese et al. [3] developed a novel procedure to determine the cohesive law in DCB specimens by measuring only the load and displacement without any external crack opening or crack advance measurement. The easiest method to measure crack advance is visual crack tracing [4], but other methods are also being investigated, e.g. acoustic emission $[4,5]$.
The other direction is the use of digital image correlation (DIC) [6]. Matta and Ramji [7] introduced an advanced method by using a microscopic tube lens to precisely capture the strain field locally at the crack tip. By DIC we can detect not only the failure of an adhesive joint, but also the delamination failure [8] in a composite plate.

Besides the development of the experimental methods, the calculation methods are also under extensive research. The primary method is to apply linear elastic fracture mechanics and evaluate strain energy density at the crack tip from finite element simulations [9]. There are three wellknown techniques with which one can simulate crack propagation in a finite element simulation. These are the virtual crack closure technique (VCCT), the cohesive zone model (CZM), and the extended finite element calculation (XFEM). VCCT assumed that when a crack is extended, the energy required to open the crack is the same, as to close it. The analysis is usually carried out based on the computed displacements and nodal forces in local elements 
around the crack tip. To model the crack growth by the CZM in the finite element modeling, a traction-separation law is assigned to cohesive elements defined in the crack path. XFEM is an extension of the conventional FEM, and it allows the presence of discontinuities in an element at the crack tip by enriching degrees of freedom with special displacement functions. Heidari-Rarani and Sayedain [10] made a comparison of these methods by simulating standard DCB-tests. They concluded that the combination of XFEM and CZM can be the most accurate method, with the limitations of more computational time and convergence difficulties. Higuchi et al. [11] also used CZM combined with XFEM and validated the numerical results with off-axis compression and open-hole tensile tests of carbon fiber reinforced composite plates. Kaushik and Ghosh [12] used CZM combined with extended isogeometric analysis (XIGA) and performed DCB-tests with carbon-epoxy prepregs. Chen et al. [13] investigated the mechanical performance of a single lap joint with non-flat interfaces. Liu et al. [14] enhanced the CZM with viscoelastic case. The authors presented a rate-dependent bilinear cohesive model that can bring robust and mesh-independent numerical results.

In the literature completely new-developed analytical models can also be found $[15,16]$. Akterskaia et al. [17] simulated the delamination process by a two-way global-local coupling approach. This novel global-local approach is a method that ensures the preservation of the dissipated energy when switching between the global and local levels.

A curiosity that CZM can not only be used to model failure of adhesive joints or composite delamination but, e.g., also to model the damage of the bone-cement interface of orthopedic implants [18].

Furthermore, next to the finite element methods with an implicit time-integration scheme, explicit methods are also a research topic. With the explicit time-integration, one can simulate short time physical processes with a very small time increment. A typical example of using explicit method is the lap-joint failure, including the failure of the composite itself as well as the adhesive [19-21].

In the literature the most researches use Abaqus as finite element solver. The other most widely used solver globally is Ansys.

This paper aims to compare the different cohesive zone models using interface elements and general contact elements, and applying exponential or bilinear cohesive law. This is performed via DCB-simulations of glass fiber reinforced composite specimens bonded with a methacrylate adhesive. The finite element solver is Ansys. The results are validated with experimental tests.

\section{Materials and experimental tests}

The investigated polymer composite is a glass fiber reinforced vinyl ester matrix composite. The material is widespread in the automotive industry, allowing direct industrial exploitation of the results. The structure of glass fiber reinforcement is a multidirectional fabric with a layer sequence of $0 \% 45^{\circ} / 90 \%-45^{\circ}$. The commercial name of the product is quadraxial fabric (Saertex - QE fabric) referring to the layer sequence. The fabric has a specific weight of $1232 \mathrm{~g} / \mathrm{m}^{2}$, in which the various directions of glass fiber layers are stitched together with thin polyester fibers. The composite sheet in question has four layers of quadraxial fabric with the same orientation and symmetrical structure. It has a thickness of $3.6 \mathrm{~mm}$. The matrix material of the composite is a vinylester resin. The commercial name is Distitron VE220, which is typically recommended for resin transfer molding (RTM) technology. $1.5 \mathrm{~m} \%$ Butanox M50 (Methyl ethyl ketone peroxide) was used as the initiator for the specimens and $0.3 \mathrm{~m} \%$ cobalt solution as the activator. The curing time was 24 hours at room temperature then 3 hours at $100{ }^{\circ} \mathrm{C}$. The specimens were manufactured using vacuum infusion.

As adhesive we used a methacrylate-based material. The commercial name is AcraLock SA $10 \mathrm{HV}$. This is a two-component, high shear-strength and stiff, high elongation, primer-free adhesive with good gap filling capabilities. According to the product data-sheet, it has an elastic modulus of $450 \mathrm{MPa}$ and a tensile strength of $22.5 \mathrm{MPa}$.

To model the deformation behavior and the failure of the joint, the stiffness parameters and the tensile- and shear-strength are required. To simulate crack propagation, the energy release rate is also a required input parameter. This value can be obtained from fracture mechanics experiments. To characterize the mode-I loading, the proper test-type is the DCB-test. The measurement layout is shown in Fig. 1. The sizes of the specimen are summarized in Table 1. The two rectangular specimens shall be glued together and then pulled apart using of a metallic hinge. In addition to the force- and displacement recording, the crack-advance shall also be measured.

To measure the crack-advance, the visual crack tracing was used. The process was recorded with a Mercury highspeed camera, then the crack-size in the function of time was obtained by manual evaluation of the scaled side-surface of the specimens. 


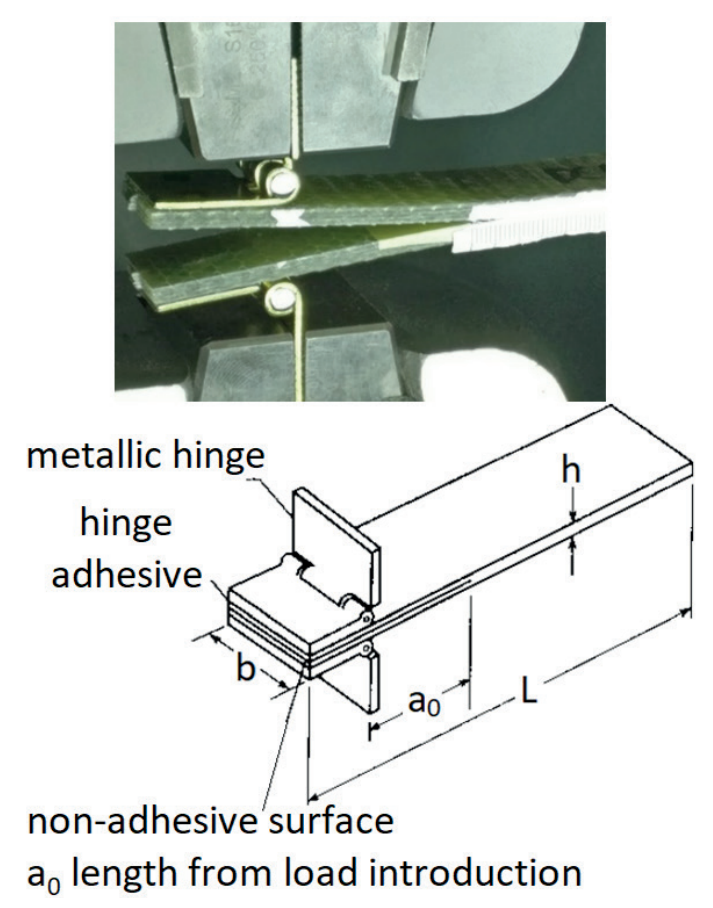

Fig. 1 DCB-test measurement layout of composite plates with adhesive joint

Table 1 DCB-test - geometrical sizes

\begin{tabular}{lcc}
\hline Description & Sign & Size [mm] \\
\hline Total length & $L$ & 127 \\
Width & $b$ & 25.4 \\
Thickness (according to lay-up) & $h$ & 7 \\
$\begin{array}{l}\text { non-adhesive surface length from } \\
\text { load introduction }\end{array}$ & $a_{0}$ & 50 \\
\hline
\end{tabular}

The evaluation of the test results was performed using the modified compliance calibration method. Detailed information about the evaluation methods can be found in another study of ours [22].

\section{Numerical analysis}

The numerical analysis was performed in Ansys 2019 R2 general finite element software. We investigated different element types and mesh-sizes, using layered shell elements and solid elements as well. Fig. 2 shows the different meshes.

In the fine-meshed models the average element size was $3.5 \mathrm{~mm}$. It equals the thickness of the composite plate, and by using shell elements, this mesh size is enough to describe the mechanical behavior with proper accuracy.

When using solid elements, we modeled three element rows through the thickness, so the out-of-plane stresses and strains could be calculated more precisely. The coarse mesh has an average element size of $8 \mathrm{~mm}$ and in the solid model there is only one element row through the thickness.
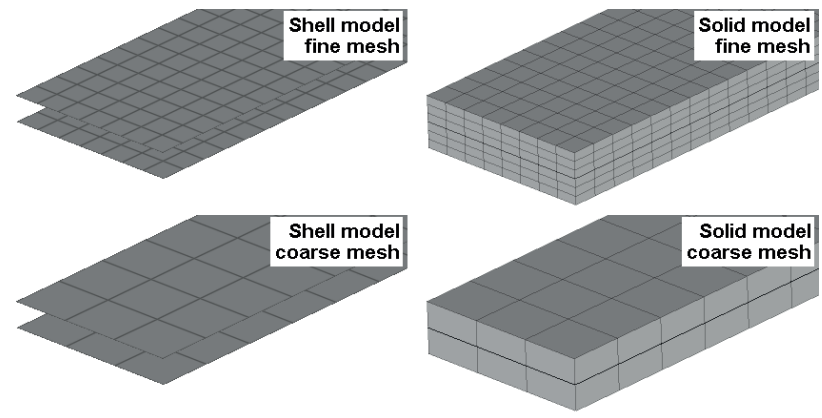

Fig. 2 Finite element models - mesh sizes

The boundary conditions are $12.5 \mathrm{~mm}$ prescribed displacements symmetrically, in an upward and downward direction. These are applied in master nodes marked with yellow arrows, shown in Fig. 3. These master nodes are constrained together with the nodes of the surfaces where the metal hinge is bonded in the physical test. These surfaces are highlighted in yellow, shown in Fig. 3. The master nodes are fixed in the longitudinal and transversal directions of the specimen and as the hinge allows the rotation about the crosswise axis in reality, this degree of freedom is free.

The material model of the composite plates is a linear elastic orthotropic material model with engineering constants summarized in Table 2. Indexes 1 and 2 refer the in-plane properties, and the index 3 refers to the outof-plane properties. As the used quadrax-type glass fiber reinforcement is isotropic in its plane, $E_{1}$ and $E_{2}$ are equal. The values were determined via bending and shear tests of the composite itself. Details of these tests are not part of the current paper.

The modeling of the adhesive failure was done by cohesive zone material models. Two different methods were investigated. We used general contact elements

Table 2 Orthotropic engineering constants of the composite plate

\begin{tabular}{ccccccc}
\hline $\begin{array}{c}E_{1} \\
{[\mathrm{MPa}]}\end{array}$ & $\begin{array}{c}E_{2} \\
{[\mathrm{MPa}]}\end{array}$ & $\begin{array}{c}E_{3} \\
{[\mathrm{MPa}]}\end{array}$ & $\begin{array}{c}\mathbf{v}_{12} \\
{[-]}\end{array}$ & $\begin{array}{c}\mathbf{v}_{13}, v_{23} \\
{[-]}\end{array}$ & $\begin{array}{c}G_{12} \\
{[\mathrm{MPa}]}\end{array}$ & $\begin{array}{c}G_{13}, G_{23} \\
{[\mathrm{MPa}]}\end{array}$ \\
\hline 11912 & 11912 & 7941 & 0.3 & 0.2 & 7035 & 4690 \\
\hline
\end{tabular}

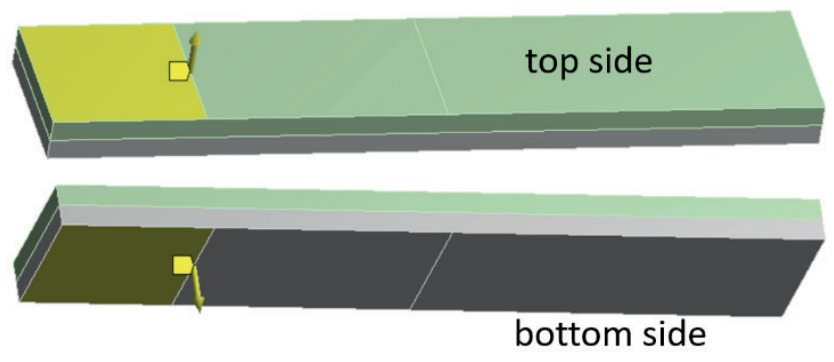

Fig. 3 Boundary conditions - applied displacements 
with bonded behavior and penalty contact algorithm and with bilinear cohesive material for shell and solid models, on the other hand we analyzed interface elements in solid models with exponential cohesive behavior. Contact elements are generally used to model different contact problems, while interface elements are mainly used to assembly components with gaskets or with delamination possibility. Interface elements can be used only with solids and require conform mesh between the parts.

The bilinear cohesive behavior is based on a model of Alfano and Crisfield [23]. The normal contact stress - separation gap is shown in Fig. 4. It has a linear hardening $(O A)$ section and then a linear softening $(A C)$ section. The maximum normal stress is reached in point $A$. Separation begins at point $A$ and is completed in point $C$. The critical fracture energy is contained in the area under the curve $O A C$. This is the energy released due to debonding. After debonding, the unloading and reloading occur along the line $O B$ at a lower slope.

The equation of the OAC-curve is the following:

$P_{n}=K_{n} u_{n}\left(1-d_{n}\right)$,

where, $P_{n}$ is the max. normal contact stress, $K_{n}$ is the normal contact stiffness, $u_{n}$ is the separation gap, $d_{n}$ is a debonding parameter which can be calculated as:

$d_{n}=\left(\frac{u_{n}-\bar{u}_{n}}{u_{n}}\right)\left(\frac{u_{n}^{c}}{u_{n}^{c}-\bar{u}_{n}}\right)$,

where $d_{n}=0$, if $\Delta_{n} \leq 1$ and $0<d_{n} \leq 1$, if $\Delta_{n}>1$, where:

$$
\Delta_{n}=\frac{u_{n}}{\bar{u}_{n}} .
$$

The critical fracture energy is calculated as:

$G_{c n}=\frac{1}{2} \sigma_{\max } u_{n}^{c}$,

where $\sigma_{\max }$ is the max. normal contact stress.

The exponential form was first published by $\mathrm{Xu}$ and Needleman [24]. The stress-separation curve is defined via the surface potential:

$\Phi\left(\sigma_{\max }, \delta\right)=e \sigma_{\max } \overline{\delta_{n}}\left(1-\left(1+\frac{\delta_{n}}{\overline{\delta_{n}}}\right) e^{-\frac{\delta_{n}}{\overline{\delta_{n}}}} e^{-\frac{\delta_{t}^{2}}{\overline{\delta_{t}^{2}}}}\right)$,

where $\sigma_{\max }$ is the maximum normal traction at the interface, $\delta_{n}$ is the normal separation across the interface, while $\delta_{t}$ is the shear-separation. If we derive the expression by $\delta_{n}$ and $\delta_{t}$, the normal- and the shear-stress can be obtained.

$\sigma=e \sigma_{\max } \frac{\delta_{n}}{\overline{\delta_{n}}} e^{-\frac{\delta_{n}}{\bar{\delta}_{n}}} e^{-\frac{\delta_{t}^{2}}{\bar{\delta}_{t}^{2}}}$

$\tau=2 e \sigma_{\max } \frac{\overline{\delta_{n}}}{\overline{\overline{\delta_{t}}}} \frac{\delta_{t}}{\overline{\overline{\delta_{t}}}}\left(1+\frac{\delta_{n}}{\overline{\delta_{n}}}\right) e^{-\frac{\delta_{n}}{\overline{\delta_{n}}}} e^{-\frac{\delta_{t}^{2}}{\overline{\bar{\delta}_{t}^{2}}}}$

\section{Results and discussion}

The experimental results are used as a reference to compare the simulation results with. The average values and scatter of the measurement series with different evaluation methods can be found in a previous paper of the authors [22]. Here one exact measurement result was chosen as reference. The force and crack-advance curves against the crosshead displacement are shown in Fig. 5. The maximum force is $165 \mathrm{~N}$, it is reached at a displacement of $7.5 \mathrm{~mm}$. At this point the failure of the adhesive begins, the crack starts to propagate and the resulting force at $25 \mathrm{~mm}$ displacement is $80 \mathrm{~N}$.

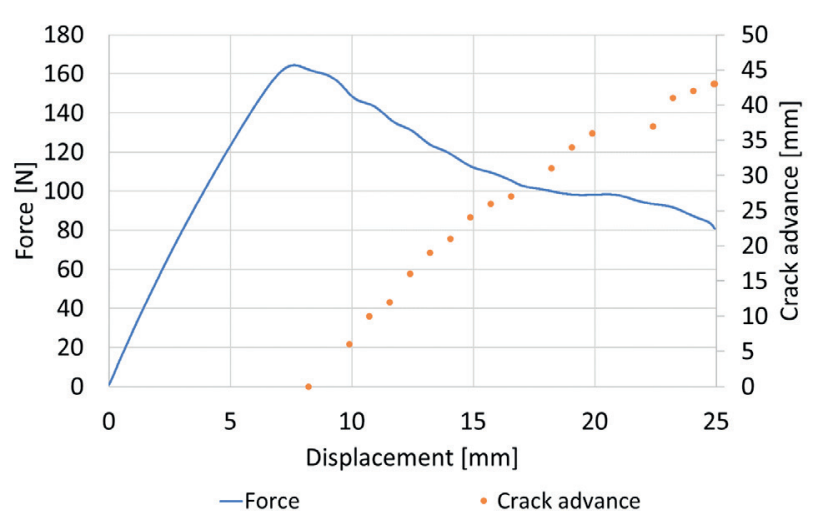

Fig. 5 DCB-test - Force- and crack advance curves

Fig. 4 Mode I dominated bilinear CZM model 
The failure type was always the cohesive failure of the adhesive material, as the used methacrylate adhesive has an excellent adhesion to the vinyl ester matrix material of the composite.

The critical energy release rate was determined by using the modified compliance calibration method. Here the crack-size is normalized with the thickness of the specimen and plotted against the cubic root of the compliance, which is the quotient of the actual force and displacement. Then a linear curve is to be fitted with the least squares method and its slope gives the correction factor $A_{1}$. The method is illustrated in Fig. 6.

By knowing the correction factor, the critical energy release rate can be calculated according to the following formula:

$G_{I}=\frac{3 P^{2} C^{2 / 3}}{2 A_{1} b h}$.

Performing this method with the measured data set, our result was $G_{I}=1517 \mathrm{~J} / \mathrm{m}^{2}$. Taking the $22.5 \mathrm{MPa}$ tensile strength of the adhesive as $\sigma_{\max }$, there is one missing parameter respectively to fit. When using bilinear cohesive law of Eq. (1), input data $K_{n}$ for normal contact stiffness is needed, and when using exponential cohesive law of Eq. (6), the value of the normal separation across the interface at maximum normal traction, $\overline{\delta_{n}}$ needs to be provided. These constants were fitted iteratively, and their values are $K_{n}=1000 \mathrm{~N} / \mathrm{mm}^{3}$ and $\overline{\delta_{n}}=0.045 \mathrm{~mm}$. The numerical results with different simulation methods are shown in Fig. 7, together with the measured force-displacement curve.

The curves show the results of the fine-meshed models. All three methods are suitable to predict the process with good accuracy. The initial slopes and the maximum forces have a relative difference of only $1 \%$ compared to the measurement. The crack propagation phase is also simulated with a proper precision as it has a maximum of $8 \%$ relative difference after the appearance of failure, but taking the whole curve into account, the correlation is very good.

The stress distribution in the is shown in Fig. 8. On the visualization of the contact pressure, the negative values represent the tension-load.

The failure starts when the stress reaches the adhesive strength of 22.5 MPa. Subsequent to that, the stress-displacement behavior follows the modeled cohesive law and the failure continues to the next element row. When investigating the stress distribution at the beginning of the adhesively bonded surface it can be seen on the top figure that the maximal loaded area is on the sides of the

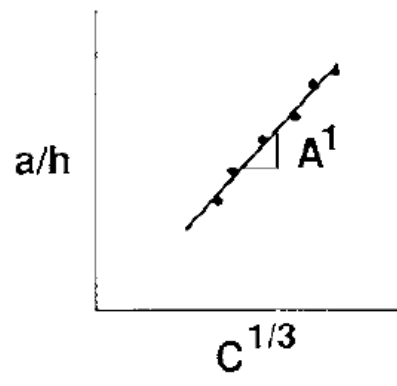

Fig. 6 Modified compliance calibration method $-A_{1}$ correction factor

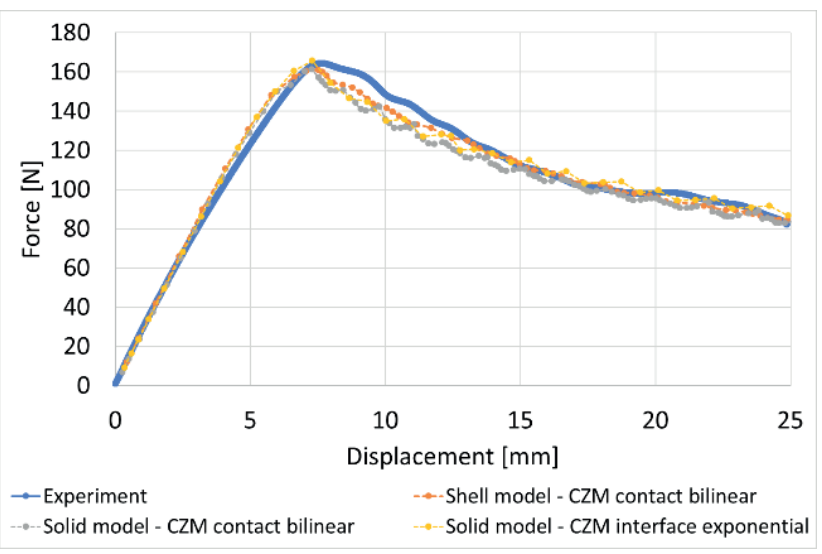

Fig. 7 DCB-tests - Force-displacement curves

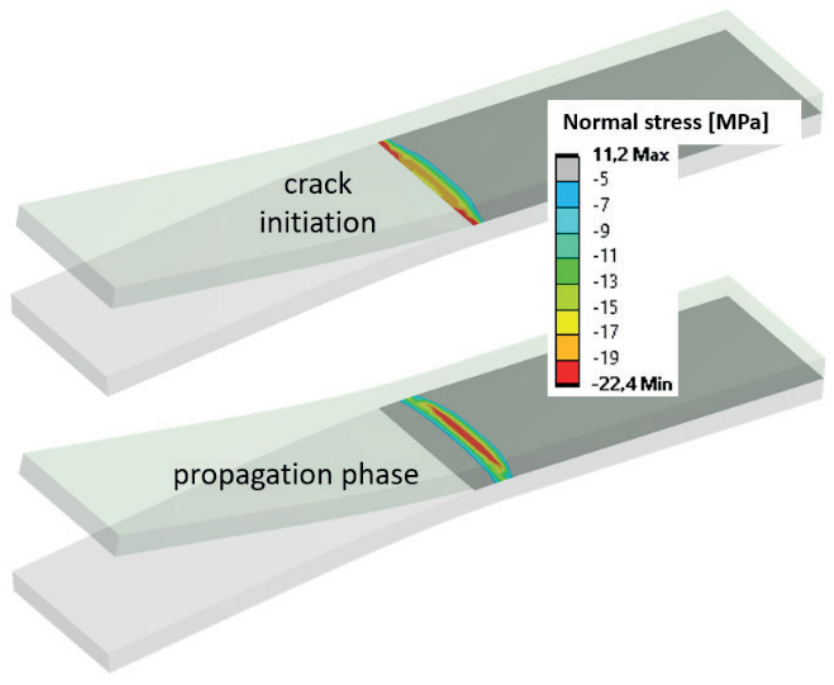

Fig. 8 Normal stress in contact elements in $\mathrm{MPa}$

specimen, while in the middle it still does not reach the limit stress. It models the process in a proper way, as in reality the crack-front is slightly parabolic, but it can be measured only via acoustic emission methods.

The calculate a realistic stress-state, it is necessary to have a fine enough mesh density. The effect of the meshsize is very important to analyze, as it affects the simulation time and can also affect the modeling effort. Fig. 9 shows the resulting force-displacement curves of the different models. 


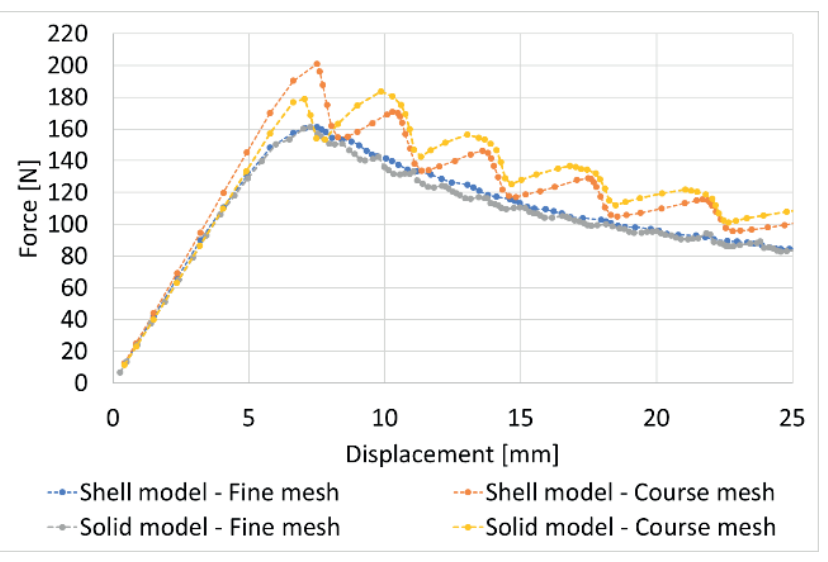

Fig. 9 DCB-tests - Effect of mesh-size

Table 3 General comparison of simulation methods

\begin{tabular}{lccc}
\hline & $\begin{array}{c}\text { Element } \\
\text { number [-] }\end{array}$ & $\begin{array}{c}\text { Number of } \\
\text { iterations [-] }\end{array}$ & $\begin{array}{c}\text { Total CPU } \\
\text { time [s] }\end{array}$ \\
\hline $\begin{array}{l}\text { Shell model } \\
\text { CZM contact bilinear }\end{array}$ & 490 & 951 & 184 \\
$\begin{array}{l}\text { Solid model } \\
\text { CZM contact bilinear }\end{array}$ & 1824 & 716 & 1823 \\
$\begin{array}{l}\text { Solid model } \\
\text { CZM interf. exponential }\end{array}$ & 1824 & 230 & 577 \\
\hline
\end{tabular}

As the finite element method is a discretization method that approximates the continuum result from below, the bigger the element size (the coarser the discretization), the smaller stress values it results in. In case the limit stress is only reached later, then we go further on the force-displacement curve with the current slope, resulting in greater maximal force. In case the failure occurs within an element with a bigger element size, the bigger size of the failed area will suddenly lower the stiffness of the assembly, which in return immediately lowers the reaction force as well. This oscillating behavior is portrayed on Fig. 9. Due to this effect, in case the behavior of the adhesive joint is the aim of the simulation, it is necessary to refine the model at least locally at the joint area.

General simulation factors such as number of elements and efficiency are compared in Table 3. All the simulations were performed under the same conditions on a PC with an Intel Core i7 $2.7 \mathrm{GHz}$ processor.

An initial substep of 100 and a minimum substep of 50 were set for all the simulations, using automatic time stepping. It means that the solver can automatically increase or decrease the step-size within these limits depending on the convergence speed. The values show that using interface elements instead of general contact elements would result in a more than 3 times faster solution regarding the number of iterations and the run-time, when comparing the models with the same number of solid elements. On the other hand, the disadvantage of this method is the need of the conform mesh between the parts. If we have a geometrically complex assembly, it can strongly increase modeling efforts. The shell model in turn brings a simulation time that is one order of magnitude less than the solid model with contact, and 3 times less than the solid model with interface. As the accuracy in deformation behavior and stress results are as good as in the other two methods, we concluded that this method is the one to be recommended the most.

\section{Conclusion}

This study has been conducted to analyze the failure modeling techniques of adhesive joints of composite plates. The investigation was done under normal loading conditions, as experimental test we performed a standard double cantilever beam test with glass fiber reinforced, vinyl ester matrix composite plates bonded with a methacrylate adhesive. The failure process was simulated with finite element simulation by using cohesive zone materials. Results of interface elements with exponential and standard contact elements with bilinear cohesive behavior were compared. Based on our results, we reached the following conclusions:

- By using the critical energy release rate obtained from the experimental test with the modified compliance calibration method, and the tensile strength of the adhesive as input data, both the bilinear cohesive contact elements and the exponential cohesive interface elements can give accurate simulation results.

- For composite plates, shell elements can serve as equally proper predictions, as solid elements.

- To model the stress-state and the failure process precisely enough, a fine mesh - with an element size of the approximate the thickness of the plate - is needed at the adhesive joint surface.

- When simulating a solid model, the use of interface elements can achieve a 3 times faster solution compared to contact elements. The shell model allows only the usage of contact elements, but it can bring a further 3 times faster solution maintaining the same accuracy. 


\section{Acknowledgment}

The project is funded by the National Research, Development and Innovation (NKFIH) Fund, Project title: "Production of polymer products by a short cycle time, automatized production technology for automotive

\section{References}

[1] Mosallam, A. S. "Analysis and Design of Adhesively Bonded Composite Joints", In: Design Guide for FRP Composite Connections, American Society of Civil Engineers, Reston, Va., USA, 2011, pp. 157-214.

https://doi.org/10.1061/9780784406120.ch05

[2] Oshima, S., Yoshimura, A., Hirano, Y., Ogasawara, T. "Experimental method for mode I fracture toughness of composite laminates using wedge loaded double cantilever beam specimens", Composites Part A: Applied Science and Manufacturing, 112, pp. 119-125, 2018.

https://doi.org/10.1016/j.compositesa.2018.05.036

[3] Arrese, A., Boyano, A., De Gracia, J., Mujika, F. "A novel procedure to determine the cohesive law in DCB tests", Composites Science and Technology, 152, pp. 76-84, 2017.

https://doi.org/10.1016/j.compscitech.2017.09.012

[4] Romhány, G., Szebenyi, G. "Interlaminar crack propagation in MWCNT/fiber reinforced hybrid composites", eXPESS Polymer Letters, 3(3), pp. 145-151, 2009.

https://doi.org/10.3144/expresspolymlett.2009.19

[5] Romhány, G., Szebenyi, G. "Interlaminar fatigue crack growth behavior of MWCNT/carbon fiber reinforced hybrid composites monitored via newly developed acoustic emission method", eXPRESS Polymer Letters, 6(7), pp. 572-580, 2012.

https://doi.org/10.3144/expresspolymlett.2012.60

[6] Gorman, J. M., Thouless, M. D. "The use of digital-image correlation to investigate the cohesive zone in a double-cantilever beam, with comparisons to numerical and analytical models", Journal of the Mechanics and Physics of Solids, 123, pp. 315-331, 2019. https://doi.org/10.1016/j.jmps.2018.08.013

[7] Matta, S., Ramji, M. "Prediction of mechanical behaviour of adhesively bonded CFRP scarf jointed specimen under tensile loading using localised DIC and CZM", International Journal of Adhesion and Adhesives, 89, pp. 88-108, 2019.

https://doi.org/10.1016/j.ijadhadh.2018.12.002

[8] Szebényi, G., Hliva, V. "Detection of Delamination in Polymer Composites by Digital Image Correlation-Experimental Test", Polymers, 11(3), Article number: 523, 2019.

https://doi.org/10.3390/polym11030523

[9] Zerrouki, A., Boulenouar, A., Mazari, M., Benguediab, M. "Experimental and FE Modeling of Mixed-Mode Crack Initiation Angle in High Density Polyethylene", Periodica Polytechnica Mechanical Engineering, 62(2), pp. 110-117, 2018.

https://doi.org/10.3311/PPme.10950

[10] Heidari-Rarani, M., Sayedain, M. "Finite element modeling strategies for $2 \mathrm{D}$ and $3 \mathrm{D}$ delamination propagation in composite $\mathrm{DCB}$ specimens using VCCT, CZM and XFEM approaches", Theoretical and Applied Fracture Mechanics, 103, Article number: 102246, 2019. https://doi.org/10.1016/j.tafmec.2019.102246 applications, with exceptional focus on the complexity and recyclability of the composite parts"; The application ID number: NVKP_16-1-2016-0046. The developers are grateful for the support.

[11] Higuchi, R., Okabe, T., Nagashima, T. "Numerical simulation of progressive damage and failure in composite laminates using XFEM/CZM coupled approach", Composites Part A: Applied Science and Manufacturing, 95, pp. 197-207, 2017. https://doi.org/10.1016/j.compositesa.2016.12.026

[12] Kaushik, V., Ghosh, A. "Experimental and numerical characterization of mode I fracture in unidirectional CRFP laminated composite using XIGA-CZM approach", Engineering Fracture Mechanics, 211, pp. 221-243, 2019. https://doi.org/10.1016/j.engfracmech.2019.01.038

[13] Chen, P. I., Wang, K. Y., Huang, H. H. "Strength and failure modes of adhesively bonded composite joints with easily fabricated nonflat interfaces", Composite Structures, 225, Article number: $111162,2019$.

https://doi.org/10.1016/j.compstruct.2019.111162

[14] Liu, P. F., Peng, X. Q., Guo, Z. Y., Leng, J. X., Jiao, L. "Viscoelastic bilinear cohesive model and parameter identification for failure analysis of adhesive composite joints", Composite Structures, 224, Article number: 111016, 2019.

https://doi.org/10.1016/j.compstruct.2019.111016

[15] Cabello, M., Zurbitu, J., Renart, J., Turon, A., Martínez, F. "A general analytical model based on elastic foundation beam theory for adhesively bonded DCB joints either with flexible or rigid adhesives", International Journal of Solids and Structures, 94-95, pp. 21-34, 2016.

https://doi.org/10.1016/j.ijsolstr.2016.05.011

[16] Cabello, M., Turon, A., Zurbitu, J., Renart, J., Sarrado, C., Martínez, F. "Progressive failure analysis of DCB bonded joints using a new elastic foundation coupled with a cohesive damage model", European Journal of Mechanics - A/Solids, 63, pp. 22-35, 2017. https://doi.org/10.1016/j.euromechsol.2016.12.004

[17] Akterskaia, M., Camanho, P. P., Jansen, E., Arteiro, A., Rolfes, R. "Progressive delamination analysis through two-way global-local coupling approach preserving energy dissipation for single-mode and mixed-mode loading", Composite Structures, 223, Article number: 110892, 2019.

https://doi.org/10.1016/j.compstruct.2019.110892

[18] Bousnane, T., Benbarek, S., Sahli, A., Serier, B., Bachir Bouiadjra, B. A. "Damage of the Bone-Cement Interface in Finite Element Analyses of Cemented Orthopaedic Implants", Periodica Polytechnica Mechanical Engineering, 62(2), pp. 173-178, 2018. https://doi.org/10.3311/PPme.11851

[19] Demiral, M., Kadioglu, F. "Failure behaviour of the adhesive layer and angle ply composite adherends in single lap joints: A numerical study", International Journal of Adhesion and Adhesives, 87, pp. 181-190, 2018. https://doi.org/10.1016/j.ijadhadh.2018.10.010 
[20] Ye, J., Yan, Y., Li, J., Hong, Y., Tian, Z. "3D explicit finite element analysis of tensile failure behavior in adhesive-bonded composite single-lap joints", Composite Structures, 201, pp. 261-275, 2018. https://doi.org/10.1016/j.compstruct.2018.05.134

[21] Ye, J., Yan, Y., Hong, Y., Guo, F. "An integrated constitutive model for tensile failure analysis and overlap design of adhesive-bonded composite joints", Composite Structures, 223, Article number: 110986, 2019.

https://doi.org/10.1016/j.compstruct.2019.110986

[22] Takács, L., Szabó, F. "Vinilészter mátrixú kompozit ragasztott kötésének törésmechanikai jellemzői" (Fracture mechanical properties of adhesive joint of vinylester matrix composite), Polimerek, 5(9), pp. 661-665, 2019. (in Hungarian)
[23] Alfano, G., Crisfield, M. A. "Finite element interface models for the delamination analysis of laminated composites: mechanical and computational issues", International Journal for Numerical Methods in Engineering, 50(7), pp. 1701-1736, 2001. https://doi.org/10.1002/nme.93

[24] Xu, X. P., Needleman, A. "Numerical simulations of fast crack growth in brittle solids", Journal of the Mechanics and Physics of Solids, 42(9), pp. 1397-1434, 1994.

https://doi.org/10.1016/0022-5096(94)90003-5 